\title{
Minor neurological signs and perceptual-motor difficulties in prematurely born children
}

\author{
Marian Jongmans, Eugenio Mercuri, Linda de Vries, Lilly Dubowitz, Sheila E Henderson
}

Department of

Psychology and

Special Needs,

Institute of Education,

University of London

$M$ Jongmans

$S$ E Henderson

Department of

Paediatrics and

Neonatology,

Hammersmith

Hospital, London

E Mercuri

L Dubowitz

Department of Neonatology,

Wilhelmina Children's

Hospital, Utrecht, The

Netherlands

L de Vries

Correspondence to:

Sheila Henderson,

Department of Psychology

and Special Needs, Institute

of Education, London

WC1H OAA.

Accepted 1 October 1996

\begin{abstract}
Aim-To examine the spectrum of neurological dysfunction and perceptualmotor difficulties at school age in a cohort of prematurely born children, and the relation of these measures to neonatal brain lesions, intelligence quotient, and behavioural adjustment.

Method-One hundred and eighty three children were tested at the age of 6 years using Touwen's Examination of the Child with Minor Neurological Dysfunction, the Movement Assessment Battery for Children (Movement ABC), the Developmental Test of Visual-Motor Integration (VMI), British Ability Scales, and Rutter Scales.

Results-Twenty six children had definite cerebral palsy and one was blind. Of the remaining 156, the proportions falling below the 15 th centile point were $31 \%$ on Touwen's Examination, $44 \%$ on the Movement ABC, and $17 \%$ on the VMI. Forty two passed all three tests. No child with a normal ultrasound scan developed cerebral palsy, whereas nearly all those with major lesions did. Minor lesions, however, were not generally predictive of later outcome. Correlations between the tests were generally low.

Conclusions-These findings stress the need to assess neurological and perceptual motor functioning separately at school age and to monitor relationships with other aspects of development.

(Arch Dis Child 1997;76:F9-F14)
\end{abstract}

Keywords: neurological signs; perceptual-motor difficulties; prematurity; follow up.

The first study to suggest that preterm birth might affect a child's later development was published in $1919 .{ }^{1}$ It was not until the 1960 s, however, that more appropriate study designs, improved technology, and better measuring techniques allowed determination of clearer relations between early risk factors associated with prematurity and later outcome.

Improvements in neonatal care in the 1970s resulted in more preterm survivors. Longitudinal studies of these children initially suggested that the prevalence of cerebral palsy remained the same, but with the survival of smaller and smaller infants and longer follow up periods the picture began to change. ${ }^{2}$ Not only did the prevalence of children with clearly identifiable cerebral palsy increase but also more children were identified with subtle perceptual-motor difficulties. Although the motor difficulties are less severe than those of children with cerebral palsy, the "clumsiness" experienced by these children affects progress in school and adjustment in many. ${ }^{3-8}$

The introduction of cranial ultrasonography in the $1980 \mathrm{~s}$ allowed identification of brain lesions in vivo and studies of the association between these lesions and later outcome. ${ }^{9-16}$ Without exception, these studies reported that cerebral palsy is more common among preterm infants who had brain lesions than among those without. In contrast, not all studies have found a significant association between subtle neurological signs or perceptual-motor problems at a later age and the presence of early brain lesions.

We aimed to examine the extent of neurological dysfunction and perceptualmotor difficulties at 6 years of age in a cohort of highly selected preterm infants treated in a tertiary care neonatal unit, the relations between neurological and perceptual-motor measures, the associations between brain lesions detected in the neonatal period and later outcome, and the relations between the children's performance on neurological, perceptual-motor, cognitive, and behavioural measures.

\section{Methods}

The study population comprised children born at or admitted to the neonatal intensive care unit of the Hammersmith Hospital in London between 1 January 1984 and 1 February 1986 who met the following criteria: (1) gestational age of less than 35 weeks; (2) a minimum of three cranial ultrasound scans 24 hours apart from each other; (3) no congenital abnormalities; and (4) a minimum of one examination in the follow up clinic between 40 weeks postmenstrual age and 2 years of age.

Three hundred and ninety seven babies of less than 35 weeks' gestation were admitted to the neonatal intensive care unit, of whom 62 died during the neonatal period (16\%). Among the 335 survivors were 219 who met all four inclusion criteria. When these children reached the age of 6 , contact was sought with their parents/guardians. Twenty nine children $(13 \%$ of eligible subjects) could not be traced, but the parents/guardians of all remaining 190 children agreed to participate in the study.

Seven children were excluded from all analyses because they had a known medical condition, or had clinical signs that suggested a condition that might interfere with their development (for example Silver-Russell syndrome, autism, severe dysmorphic features). 
Table 1 Comparison between the study and reference groups on the measure; values are median (range)

\begin{tabular}{llll}
\hline & Preterm & Reference & $P$ \\
\hline $\begin{array}{l}\text { Neurological and perceptual-motor functioning } \\
\text { Touwen }\end{array}$ & $38.0(17-46)$ & $40.5(31-46)$ & 0.0060 \\
$\quad$ Movement ABC & $4.5(0-23.5)$ & $2.0(0-26)$ & 0.0001 \\
$\quad$ VMI & $8(3-15)$ & $9(4-15)$ & 0.0265 \\
$\begin{array}{l}\text { Cognitive ability and behaviour } \\
\text { BAS }\end{array}$ & $106(12)$ & $115(13)$ & 0.0001 \\
$\quad \begin{array}{lll}\text { Rutter scale } \\
\quad \text { Parents }\end{array}$ & $9(2-30)$ & $12(1-45)$ & 0.0001 \\
$\quad$ Teachers & $4(0-21)$ & $4(0-35)$ & 0.1373 \\
\hline Mean (SD) & &
\end{tabular}

Of the 183 children remaining, 90 were boys and 93 were girls. At birth, the children weighed between 625 and $2500 \mathrm{~g}$ (mean 1304; SD 395). Gestational ages ranged from 25 to 34 weeks (mean 30; SD 2). At the time of testing, their mean age was 76 months (SD 3 months).

Because of the restricted age range of our cohort, we elected to use local norms for this study rather than those reported in the test manuals. For the measures of cognitive ability and behaviour the data from a sample of 215 full term children were already available in our department for comparison with the study group. For the measures of neurological and perceptual-motor functioning no local norms were available at the time of the study, so we assessed two groups of 66 and 88 schoolchildren, respectively, matched for age, gender, and racial distribution to the study group.

The ultrasound scans performed with an ATL Mark III mechanical sector scanner fitted with a 5 or $7.5 \mathrm{MHz}$ transducer were classified by one neonatologist (LdV). Lesions were classified according to the grading system described by de Vries et al. ${ }^{17}{ }^{18}$

FOLLOW UP ASSESSMENT

The children were assessed using a structured neurological examination and standardised measures of perceptual-motor competence, cognitive ability, and behaviour.

\section{Assessment of neurological functioning}

Touwen's Examination of the Child with Minor Neurological Dysfunction ${ }^{19}$ was administered. This examination consists of a number of items grouped under the following headings: sensorimotor apparatus, posture, balance of trunk, coordination of extremities, fine manipulative ability, (dys)kinesia, gross motor functions, quality of motility, associated movements, and the visual system. The examination was administered in full, with the exception of items assessing the visual system, which was evaluated with a more detailed examination. ${ }^{20}$ This left 46 items out of the 55 originally included. Optimality scores therefore range from 0 to 46 with lower scores indicating less optimal performance. According to the distribution of scores obtained by the reference sample, total scores of 36 or lower (15th centile) were considered as "borderline" and scores of 33 or lower ( 5 th centile) as "abnormal" minor neurological impairment.

\section{Assessment of perceptual-motor competence}

Two assessments were used to provide contrasting but complementary information on perceptual-motor abilities. The first is a global test of motor competence, assessing both gross and fine motor coordination. The second test focuses on visual-motor integration, requiring a graphic response to a visual input.

Movement Assessment Battery for Children (Movement $A B C$ ) - This assessment comprises eight items which sample manual dexterity, ball skills, and balance. ${ }^{21}$ Raw scores on each item are converted to normative scores ranging from 0 to 5 . These scores are then summed to produce a total score ranging from 0 to 40 , with high scores indicating poor performance. According to the distribution of scores obtained by the reference sample, total scores of more than 5.5 ( 15 th centile) were considered as borderline and scores of more than 10.5 ( 5 th centile) as abnormal perceptual-motor performance.

Developmental Test of Visual-Motor Integration (VMI) - This is a paper and pencil task in which a child copies a series of geometric shapes of increasing difficulty. ${ }^{22}$ The standard score reflects the accuracy of the copies and can range from 0 to 19 , the lower the score, the less competent the performance. According to the distribution of scores obtained by the reference sample, standard scores of 6 ( 15 th centile)

Table 2 Individual data of preterm children with mild to moderate cerebral palsy

\begin{tabular}{|c|c|c|c|c|c|c|c|}
\hline & \multicolumn{4}{|c|}{ Neurological and perceptual-motor functioning } & \multicolumn{3}{|c|}{ Cognitive ability and behaviour } \\
\hline & \multirow[b]{2}{*}{ Classification } & \multirow[b]{2}{*}{ Touwen } & \multirow[b]{2}{*}{ Movement $A B C$} & \multirow[b]{2}{*}{$V M I$} & \multirow[b]{2}{*}{$I Q$} & \multicolumn{2}{|l|}{ Rutter } \\
\hline & & & & & & Parent & Teacher \\
\hline 1 & Quadriplegia & Abnormal & Abnormal & Abnormal & Abnormal & & \\
\hline 2 & $\mathrm{Di} /$ quadriplegia & Abnormal & Abnormal & Abnormal & Abnormal & Abnormal & Abnormal \\
\hline 3 & $\mathrm{Di} /$ quadriplegia & Abnormal & Abnormal & Abnormal & Abnormal & Abnormal & Abnormal \\
\hline 4 & $\mathrm{Di} /$ quadriplegia & Abnormal & Abnormal & Abnormal & Abnormal & Abnormal & Abnormal \\
\hline 5 & Hemi/triplegia & Abnormal & Abnormal & Normal & Normal & Normal & Abnormal \\
\hline 6 & Diplegia & Abnormal & Abnormal & Normal & Borderline & Abnormal & Normal \\
\hline 7 & Diplegia & Abnormal & Abnormal & Abnormal & Abnormal & Abnormal & Normal \\
\hline 8 & Diplegia & Abnormal & Abnormal & Borderline & Normal & Normal & \\
\hline 9 & Diplegia & Abnormal & Borderline & Normal & Normal & Normal & Normal \\
\hline 10 & Hemiplegia ${ }^{\star}$ & Abnormal & & & Abnormal & Abnormal & \\
\hline 11 & Hemiplegia & Abnormal & Abnormal & Abnormal & Normal & Normal & \\
\hline 12 & Hemiplegia & Abnormal & Abnormal & Borderline & Normal & Normal & Abnormal \\
\hline 13 & Hemiplegia & Abnormal & Abnormal & Abnormal & Abnormal & Abnormal & Normal \\
\hline 14 & Hemiplegia & Abnormal & Abnormal & Abnormal & Abnormal & Normal & Normal \\
\hline 15 & Hemiplegia & Abnormal & Abnormal & Normal & Normal & Normal & - \\
\hline
\end{tabular}


Table 3 Number of preterm children without cerebal palsy $(n=156)$ with abnormal, borderline, or normal scores on the Movement ABC and Touwen examination

\begin{tabular}{llll}
\hline \multirow{2}{*}{ Touwen Examination } & \multicolumn{2}{l}{ Movement $A B C$} \\
\cline { 2 - 4 } & Abnormal $(n=30)$ & Borderline $(n=39)$ & Normal $(n=87)$ \\
\hline Abnormal $(\mathrm{n}=26)$ & 12 & 12 & 2 \\
Borderline $(\mathrm{n}=22)$ & 47 & 4 & 14 \\
Normal $(\mathrm{n}=108)$ & 14 & 23 & 71 \\
\hline
\end{tabular}

were considered as borderline and 5 or lower ( 5 th centile) as abnormal performance on this test.

Assessment of cognitive ability and behaviour British Ability Scales (BAS)—Cognitive abilities were assessed using the short form of the BAS. ${ }^{23}$ This includes two verbal tests, involving naming vocabulary and the appreciation of similarities in the meanings of words, and two non-verbal tests, digit recall and matrices. The mean $\mathrm{T}$ score on these four scales is used to compute the short form intelligence quotient (IQ) estimate. According to the distribution of scores obtained by the reference sample, scores of 100 or lower (15th centile) were considered as borderline and scores of 92 or lower (5th centile) as definite cognitive impairment.

Rutter Scales-The parents' scale A $^{24}$ consists of 31 brief statements, and parents/guardians are asked to indicate the extent to which each statement applies to their child. Items are scored on a scale of 0 to 2 and are summed to obtain a total score, with high scores indicating more behaviour problems. The teachers' scale $\mathrm{B}^{25}$ consists of 26 statements and the same scoring system is used. With the use of the cut off points recommended by Rutter, children with total scores of 13 or more on the parents' scale and 9 or more on the teachers' scale were considered to show definite behaviour problems. No cut off point was available to determine borderline status.

DATA ANALYSES

Non-parametric (Mann-Whitney U, KruskalWallis one way analysis of variance, Spearman's correlation coefficients) and parametric (one way analysis of variance) tests of significance were used to identify differences between the premature and reference groups. For those data not normally distributed median scores were calculated, otherwise mean scores are

Table 4 Number of preterm children without cerebal palsy $(n=156)$ with abnormal borderline or normal scores on the VMI and Touwen Examination

\begin{tabular}{|c|c|c|c|}
\hline \multirow[b]{2}{*}{ Touwen Examination } & \multicolumn{3}{|l|}{$V M I$} \\
\hline & Abnormal $(n=15)$ & Borderline $(n=12)$ & Normal $(n=129)$ \\
\hline Abnormal $(n=26)$ & 5 & 4 & 17 \\
\hline Borderline $(n=22)$ & 3 & 1 & 18 \\
\hline Normal $(n=108)$ & 7 & 7 & 94 \\
\hline
\end{tabular}

Table 5 Number of preterm children without cerebal palsy $(n=156)$ with abnormal, borderline, or normal scores on the VMI and Movement ABC

\begin{tabular}{llll}
\hline \multirow{2}{*}{ Movement $A B C$} & \multicolumn{2}{l}{} & \\
\cline { 2 - 4 } & Abnormal $(n=15)$ & Borderline $(n=12)$ & Normal $(n=129)$ \\
\hline Abnormal $(\mathrm{n}=30)$ & 7 & 5 & 18 \\
Borderline $(\mathrm{n}=39)$ & 5 & 4 & 30 \\
Normal $(\mathrm{n}=87)$ & 3 & 3 & 81 \\
\hline
\end{tabular}

reported. Because of the large number of comparisons, the probability level was set at 0.01 .

\section{Results}

\section{CLINICAL ASSESSMENT}

Twenty six of the 183 children in the study group $(14 \%)$ had cerebral palsy. Eleven of them and one blind child were so severely impaired that they were unable to perform any of the assessments. The remaining 15 children with cerebral palsy attempted parts of the battery.

Table 1 shows the results of the preterm group, excluding the blind child and all children with cerebral palsy, and reference groups. The differences between the groups were statistically significant on all measures, except the teachers' ratings of the children's behaviour on the Rutter Scales.

Details of the 15 children with mild to moderate cerebral palsy who could perform parts of the assessments are shown in table 2. As a group they differed significantly from preterm children without cerebral palsy on all measures except behaviour at home and at school.

The results for the 156 preterm children without cerebral palsy are described in tables 3 to 5, showing the overlap between two tests. Tables 3 and 4 show that 48 of the 156 children (31\%) had abnormal or borderline scores on the Touwen Examination which was associated with failure on the Movement ABC in 32 and on the VMI in 13. Of the 108 children who showed no evidence of neurological dysfunction, 37 had abnormal or borderline scores on the Movement ABC and 14 failed the VMI. Sixty nine of the 156 children (44\%) had abnormal or borderline scores on the Movement ABC. A third of these failed the VMI (table 5). Sixty six children (42\%) passed all three tests. Spearman rank order correlations between the three tests are shown in table 10 .

CLINICAL ASSESSMENT, GESTATIONAL AGE, AND BIRTH WEIGHT

Table 6 shows the relations between gestational age and performance on the three assessments. Kruskal-Wallis one-way analyses of variance performed on these data revealed that the differences between the groups only reached our preset level of significance on the Movement ABC. Differences between the groups on the Touwen Examination and VMI approached significance $(P<0.02)$. Further analysis of the Movement ABC scores then showed that the children born between 25 and 29 weeks' gestation were significantly worse than children born between 33 and 34 weeks.

Table 7 shows the relation between test performance and birth weight. Significant group differences were only obtained on the VMI. Post hoc analysis revealed that children weighing less than $1000 \mathrm{~g}$ differed significantly from those above $1500 \mathrm{~g}$ on this test.

Children with a birth weight appropriate for their gestational age $(n=119)$ did not differ from those whose birth weight fell below the 10 th centile for their gestational age $(n=52)$ on any of the three measures (table 8 ). 
Table 6 Outcome in relation to gestational age excluding the 12 untestable children $(n=171)$; values are median (range)

\begin{tabular}{|c|c|c|c|c|c|}
\hline & $\begin{array}{l}25-27 \text { weeks } \\
(n=31)\end{array}$ & $\begin{array}{l}28-29 \text { weeks } \\
(n=38)\end{array}$ & $\begin{array}{l}30-32 \text { weeks } \\
(n=78)\end{array}$ & $\begin{array}{l}33-34 \text { weeks } \\
(n=24)\end{array}$ & $P^{\star}$ \\
\hline Touwen Test & $34(12-43)$ & $37(12-46)$ & $38(0-46)$ & $40(33-45)$ & 0.0150 \\
\hline Movement ABC & $11(0-40)$ & $7.3(0-39)$ & $4.5(0-40)$ & $2.3(0-14)$ & 0.0010 \\
\hline VMI & $8(0-13)$ & $8(0-11)$ & $8(0-14)$ & $9(5-15)$ & 0.0177 \\
\hline
\end{tabular}

^Kruskal-Wallis one way analysis of variance.

Table 7 Outcome in relation to birth weight excluding the 12 untestable children $(n=171)$; values are median (range)

\begin{tabular}{lllll}
\hline & $<1000 g(n=39)$ & $1000-1499 g(n=82)$ & $1500-2499 g(n=50)$ & $P^{*}$ \\
\hline Touwen Test & $35(12-45)$ & $38(0-46)$ & $38(3-45)$ & 0.1828 \\
Movement ABC & $9(0-40)$ & $5.3(0-40)$ & $4(0-39)$ & 0.0957 \\
VMI & $7(1-11)$ & $8(0-13)$ & $9(3-15)$ & 0.0020 \\
\hline
\end{tabular}

^Kruskal-Wallis one way analysis of variance.

Table 8 Outcome in the relation to the combination of gestational age and birth weight excluding the 12 untestable children $(n=171)$; values are median (range)

\begin{tabular}{llll}
\hline & $A G A(n=119)$ & $S G A(n=52)$ & $P^{\star}$ \\
\hline Touwen Test & $38(0-46)$ & $38(13-46)$ & 0.2277 \\
Movement ABC & $6(0-40)$ & $5(0-40)$ & 0.5457 \\
VMI & $8(0-15)$ & $8(1-14)$ & 0.3435 \\
\hline
\end{tabular}

^Mann-Whitney U test. AGA=appropriate for gestational age; SGA=small for gestational age.

CLINICAL ASSESSMENT AND BRAIN LESIONS ON NEONATAL ULTRASOUND

Table 9 shows the results of the clinical assessment in relation to brain lesions. None of the 64 children with normal neonatal ultrasound scans developed cerebral palsy. However, eight children were abnormal on the Touwen Examination, five were abnormal on the Movement ABC, of whom two were abnormal on both. Thirty six children passed all three assessments.

Eighty one children had minor haemorrhagic or ischaemic lesions or a combination of these. Four children, all with ultrasonographic flares, had cerebral palsy and one child with a combination of lesions was visually impaired. Fifteen children failed the Touwen Test, of whom eight also failed the Movement ABC and/or VMI. A further 17 children failed the Movement ABC and/or VMI but not the Touwen Examination. Twenty seven children passed all three assessments.

None of the seven children with ventricular dilatation present at birth developed cerebral palsy. However, none achieved a normal score on any of the three assessments.

The child with an isolated small cyst and one of the two children with a grade IIb haemorrhage passed all three assessments. However, the two children with a combination of a grade IIb haemorrhage and another lesion both had moderate cerebal palsy.

Six children had grade III haemorrhages. Four developed mild or moderate cerebral palsy, one failed the Movement $\mathrm{ABC}$ and one the VMI.

Six children had an infarct in isolation or combined with another lesion. One child developed severe and one child mild to moderate cerebral palsy. Two children failed the Touwen Test of whom one also failed the Movement ABC. One child failed the Movement ABC only and one passed all three assessments.
Fourteen children had cystic periventricular leucomalacia, subcortical leucomalacia, or a combination of these lesions. All 14 developed cerebral palsy, which was mild to moderate in three and severe in 11 .

\section{CLINICAL ASSESSMENT IN RELATION TO}

COGNITIVE ABILITY AND BEHAVIOUR

Table 10 illustrates the relations between the BAS and Rutter scores for children without cerebral palsy and their performance on the Touwen examination, Movement ABC, and VMI. All three neurological and perceptualmotor tests were significantly correlated with each other, although the coefficients were generally low. The children's scores on the Touwen Examination and the Movement $\mathrm{ABC}$ were unrelated to their IQ scores as measured by the BAS. In contrast, their VMI scores were correlated with IQ $\left(r_{s}=0.35 ; \mathrm{P}=0.0010\right)$. Parents' ratings on the Rutter scores were unrelated to any other score whereas teachers' ratings related to both the Movement $\mathrm{ABC}\left(r_{s}=0.27\right.$; $\mathrm{P}=0.004)$ and VMI $\left(r_{s}=0.31 ; \mathrm{P}=0.001\right)$.

In table 11, the overlap between the tests is shown for the children whose scores fell into the abnormal range only. Of the $32 \%$ who had abnormal scores on the Touwen Examination, Movement ABC and/or VMI, half had similarly low scores on the BAS and/or Rutter Scales. In contrast, another $31 \%$ of children who fell below the 5th centile on the BAS and/or Rutter scales showed no neurological signs and passed the two perceptual-motor tests.

\section{Discussion}

Several previous studies have shown that many preterm children without cerebral palsy show minor neurological signs and/or perceptualmotor difficulties at school age. However, none of these studies assessed both in the same population. While some authors ${ }^{10}{ }^{26}$ used assessments such as Touwen's Examination only, others evaluated perceptual-motor competence without a detailed assessment of minor neurological signs. ${ }^{13-15}$ This is the first study to employ a standardised neurological examination for major and minor signs as well as standardised perceptual-motor assessments in children born prematurely.

Our observations agree with previous studies showing a significantly higher prevalence of neurological signs at school age in preterm children compared with their peers. Some $14 \%$ of these children had clearly identifiable cerebral palsy while a further $16 \%$ fell below the 5th centile on the Touwen Examination. A similar proportion of the children without cerebral palsy had abnormal scores on the Movement ABC (19\%). Although these two assessments were significantly correlated with each other, the value of this correlation was low, accounting for only $25 \%$ of the common variance. There were also children who failed on the Touwen Examination and passed on the Movement ABC and the converse. These findings suggest that, although both the Touwen Examination and the Movement ABC evaluate subtle levels of impairment, they measure 
Table 9 Neonatal brain lesions in relation to outcome

\begin{tabular}{|c|c|c|c|c|c|c|c|c|c|c|}
\hline \multirow[b]{3}{*}{ Ultrasound findings } & \multirow[b]{3}{*}{ No } & & & \multicolumn{6}{|c|}{$\begin{array}{l}\text { Minor neurological and/pr perceptual-motor } \\
\text { problems }\end{array}$} & \multirow{3}{*}{$\begin{array}{l}\text { Normal on } \\
\text { all three } \\
\text { assessments }\end{array}$} \\
\hline & & \multicolumn{2}{|c|}{ Cerebal palsy } & \multicolumn{2}{|c|}{ Touwen } & \multicolumn{2}{|c|}{$\begin{array}{l}\text { Movement } \\
A B C\end{array}$} & \multicolumn{2}{|c|}{$V M I$} & \\
\hline & & Severe & Moderate & $A$ & $B$ & $A$ & $B$ & $A$ & $B$ & \\
\hline Normal & 64 & - & - & 8 & 6 & 5 & 17 & - & 4 & 36 \\
\hline Grade I haemorrhage & 10 & - & - & 1 & 1 & 3 & 2 & 3 & - & 4 \\
\hline Grade IIa haemorrhage & 8 & - & - & 1 & - & 2 & - & - & 1 & 6 \\
\hline Flares & 45 & - & 4 & 9 & 7 & 12 & 11 & 6 & 3 & 11 \\
\hline Grade I haemorrhage+flares & 10 & - & - & 2 & 2 & - & 4 & 1 & - & 3 \\
\hline Grade IIa haemorrhage+flares & 8 & - & - & 2 & 2 & 3 & 2 & 2 & 2 & 3 \\
\hline Ventricular dilatation at birth & 7 & - & - & 1 & 1 & 2 & 1 & 2 & 2 & - \\
\hline Cyst & 1 & - & - & - & - & - & - & - & - & - \\
\hline Grade IIb haemorrhage & 2 & - & - & - & 1 & - & - & - & - & 1 \\
\hline Grade IIb haemorrhage+others & 2 & - & 2 & - & - & - & - & - & - & - \\
\hline Grade III haemorrhage & 6 & - & 4 & - & 2 & 1 & 1 & 1 & - & - \\
\hline Infarct & 2 & - & 1 & - & - & - & - & - & - & 1 \\
\hline \multicolumn{11}{|l|}{ Infarct and } \\
\hline Grade IIa haemorrhage+flares & 1 & - & - & 1 & - & - & 1 & - & - & - \\
\hline Grade IIb haemorrhage & 2 & 1 & - & 1 & - & 1 & - & - & - & - \\
\hline Grade IIb haemorrhage+flares+cyst & 1 & - & - & - & - & 1 & - & - & - & - \\
\hline PVL & 7 & 7 & - & - & - & - & - & - & - & - \\
\hline \multicolumn{11}{|l|}{ PVL and } \\
\hline Grade IIa haemorrhage & 1 & 1 & - & - & - & - & - & - & - & - \\
\hline Grade IIb haemorrhage & 1 & 1 & - & - & - & - & - & - & - & - \\
\hline $\begin{array}{l}\text { Grade IIb } \\
\text { haemorrhage+infarct+cyst }\end{array}$ & 1 & 1 & - & - & - & - & - & - & - & - \\
\hline SCL & 3 & 3 & - & - & - & - & - & - & - & - \\
\hline PVL+SCL & 1 & 1 & - & - & - & - & - & - & - & - \\
\hline Total & 182 & 15 & 11 & 26 & 16 & 30 & 39 & 15 & 12 & 55 \\
\hline
\end{tabular}

Numbers in cells are not mutually exclusive. $\mathrm{PVL}=$ periventricular leucomalacia; $\mathrm{SCL}=$ subcortical leucomalacia.

Table 10 Spearman rank order correlation coefficients (P values) for all measures $(n=156)$

\begin{tabular}{|c|c|c|c|c|c|}
\hline & Movement $A B C$ & $V M I$ & $B A S$ & Rutter Parents'Scale & Rutter Teachers' Scale \\
\hline Touwen & $-0.35(0.0001)$ & $0.25(0.002)$ & $0.05(0.578)$ & $(0.099)$ & $-0.16(0.097)$ \\
\hline Movement ABC & & $-0.28(0.0001)$ & $-0.10(0.232)$ & $0.08(0.321)$ & $0.27(0.004)$ \\
\hline VMI & & & $0.35(0.0001)$ & $0.09(0.265)$ & $0.31(0.001)$ \\
\hline BAS & & & & $0.09(0.270)$ & $0.27(0.004)$ \\
\hline Rutter parents' scale & & & & & $0.10(0.284)$ \\
\hline
\end{tabular}

different aspects of functioning and so both are needed to obtain an overview of a child's difficulties. Although preterm children differed significantly from the reference group on the VMI, far fewer children fell below the 5th centile on this assessment. It is possible that this is because the scoring system of the VMI is so crude that it fails to identify minor impairment. Alternatively, there may actually be more children who can manage this very focused task.

The combination of neurological and perceptual-motor measures together with a detailed evaluation of cranial ultrasound scans was particularly useful in exploring the relationship between brain lesions and later outcome. Among children with major lesions who developed cerebral palsy but were able to complete parts of the tests, we found a wide range of neurological and perceptual-motor functioning. For example, four children with cerebral palsy passed the VMI without difficulty.

Table 11 Relation between definite neurological/perceptual-motor problems and definite cognitive/behaviour problems for preterm children without cerebal palsy $(n=156)$; values are per cents

\begin{tabular}{llll}
\hline & \multicolumn{2}{l}{$\begin{array}{l}\text { Abnormal score on the Touwen } \\
\text { Examination, Movement ABC, } \\
\text { andlor VMI }\end{array}$} & \multirow{2}{*}{ Abnormal score on the BAS and/or Rutter Scales } \\
\cline { 2 - 3 } & Yes & No & Total \\
\hline Yes & 16 & 31 & 47 \\
No & 16 & 37 & 53 \\
Total & 32 & 68 & 100 \\
\hline
\end{tabular}

The combined assessments were also useful in showing that there is no simple relation between the presence or absence of a minor brain lesion and later outcome. As we have already reported ${ }^{12}$ in a group of children who showed persistent flares on neonatal ultrasonography, only a few developed cerebral palsy although the majority showed minor neurological signs and/or perceptual-motor problems. Similarly, although none of the children with minor haemorrhages developed cerebral palsy, one third showed difficulties on our assessments. We were particularly interested to note that no child with a normal scan developed cerebral palsy but many showed minor neurological signs and/or perceptualmotor problems, suggesting that the absence of an observable brain lesion in preterm infants does not guarantee a completely normal outcome.

Although the infants in our cohort with a relatively high birth weight or more advanced gestational age were the ones admitted or referred because of illness, it was still the children with the lowest birth weight and the lowest gestational age who were the most affected at 6 years of age in their neurological and perceptual-motor development. This finding is in keeping with other studies. ${ }^{714}$ When birth weight was considered in relation to gestational age, we found no difference between those children who were small for gestational age and the rest. 
The relation between the children's IQs and their performance on the Touwen Examination and the Movement ABC was negligible, suggesting that cognitive factors had not influenced our estimates of their neurological status and perceptual-motor competence. In contrast, the correlation between IQ and VMI was significant. Whereas the parents' ratings of their children's behaviour were unrelated to performance on the neurological and perceptual-motor tests, teachers' ratings were related to the two functional tests, Movement $\mathrm{ABC}$ and VMI.

From another perspective, it may be useful to note that only $50 \%$ of the children with abnormal neurological and/or perceptualmotor performance in our cohort showed additional cognitive or behaviour problems at 6 years of age. Many children identified as clumsy at school age find it difficult to make progress in school and often experience adjustment problems, ${ }^{27}$ so it will be important to follow these children for longer. In fact, in one study, the presence of movement difficulties at 6 years was found to be the best predictor of reading difficulties at 8 years in infants of low birth weight. ${ }^{28}$

As our study group were sampled from a tertiary care centre-that is, a highly skewed population of at risk children, we expected that their outcome would be more unfavourable than in a population based study such as the recently published Scottish Low Birth Weight Study. ${ }^{7}$ Nevertheless, there was a surprisingly high proportion of preterm children who showed minor neurological signs and/or perceptual motor difficulties in the absence of major neurological impairment. As the presence of these problems may affect the children's ability to function in everyday life, it is essential that they are comprehensively assessed so that meaningful intervention can be planned when necessary.

1 Ylppo A. Das Wachstum der Fruhgeborenen von der Geburt bis zum Schulalter. Zeitschrift für Kinderheilkunde 1919;24:111-78.

2 Hagberg B, Hagberg G. The origins of cerebral palsy. Recent advances in paediatrics, XI. Edinburgh, London: Churchill Livingstone, 1993:67-83.

3 Black B, Brown C, Thomas DA. A follow-up study of 58 preschool children less than 1500 grams birthweight. Aust preschool children less than

4 Calame A, Fawer CL, Claeys V, et al. Neurodevelopmental outcome and school performance of very low-birthweigh infants at 8 years of age. Eur F Pediatr 1986;145:461-6.

5 Klein NK, Hack M, Breslan H. Children who were very low birthweight: development and academic achievement at nine years of age. F Dev Behav Pediatr 1989;10:32-7.
6 Saigal S, Szatmari P, Rosenbaum P, Campbell D, King S. Intellectual and functional status at school entry of children who weighed 1000 gram or less at birth: a regional perspective of births in the 1980s. F Pediatr 1990;116:409-16

7 Hall A, McLeod A, Counsell C, Thomson L, Mutch L. School attainment, cognitive ability and motor function in a total Scottish very-low-birthweight population at eight years: a controlled study. Dev Med Child Neurol 1995;37:1037-50

8 Veen S, Ens-Dokkum MH, Schreuder AM, VerlooveVanhorick SP, Brand R, Ruys JH. Impairments, disabilities and handicaps of very preterm and very low-birthweight and handicaps of very preterm and very low-b 5 years of age. Lancet 1991;338:33-6.

9 Cooke RWI. Early and late cranial ultrasonographic appearances and outcome in very low birthweight infants. Arch ;62:931-7.

10 Fawer CL, Calame A. Significance of ultrasound appearances in the neurological development and cognitive abilities of preterm infants at 5 years. Eur $\mathcal{f}$ Pediatr 1991;150:515-20

11 Ford LM, Steichen J, Steichen-Ash PA, Babcock D, Fogelson $\mathrm{MH}$. Neurological status and intracranial hemorrhage in very-low-birthweight preterm infants: outcomes at 1 year and 5 years. Am 7 Dis Child 1989;143:1186-90.

12 Jongmans $M$, Henderson S, de Vries L, Dubowitz L. Duration of periventricular densities in preterm infants and tion of periventricular densities in preterm infants and 1993;69:9-13.

13 Levene M, Dowling S, Graham M, Fogelman K, Galton M, Philips M. Impaired motor function (clumsiness) in five year old children: correlation with neonatal ultrasound scans. Arch Dis Child 1992;67:687-90.

14 Marlow N, Roberts BL, Cook RWI. Motor skills in extremely low birthweight children at the age of six years. Arch Dis Child 1989;64:839-47.

15 Roth SC, Baudin J, McCormick DC, et al. Relation between ultrasound appearance of the brain of very preterm infants and neurodevelopmental impairment at eight years. Dev Med Child Neurol 1993;35:755-68.

16 Van de Bor M, Ens-Dokkum M, Schreuder AM, Veen S, Brand R, Verloove-Vanhorick SP. Outcome of periventricular-intraventricular haemorrhage at five years of age. Dev Med Child Neurol 1993;35:33-41.

17 De Vries LS, Dubowitz LMS, Dubowitz V, et al. Predictive value of cranial ultrasound: a reappraisal. Lancet $1985 ; \mathbf{i i}: 137-40$

18 De Vries LS, Eken P, Dubowitz LMS. The spectrum of leukomalacia using cranial ultrasound. Behav Brain Res 1992;49:1-6.

19 Touwen BCL. Examination of the child with minor neurological dysfunction. Clinics in Developmental Medicine 71 . London: William Heinemann Medical Books, 1979.

20 Jongmans M, Mercuri E, Henderson S, de Vries L, Sonksen P, Dubowitz L. Visual function of prematurely born children with and without perceptual-motor difficulties. Early Hum Dev 1996;45:73-82.

21 Henderson SE, Sugden DA. Movement assessment battery for children. London: The Psychological Corporation, 1992.

22 Beery KE. Developmental test of visual-motor integration. Cleveland: Modern Curriculum Press, 1989.

23 Elliott, CD, Murray, DJ, Pearlson LS. The British abilities scales. Windsor: NFER-Nelson Publishing, 1983.

24 Rutter M. Classification and categorisation in child psychiatry. F Child Psychol Psychiatry 1965;6:71-83.

25 Rutter M. A children's behaviour questionnaire for completion by teachers: preliminary findings. F Child Psychol Psychiatry 1967;8:1-11.

26 Largo RH Molinar L, Kundu S, Hunziker U, Duc G. Neurological outcome in high risk appropriate for gestational age preterm children at early school age. Eur $\mathcal{F}$ Pediatr 1990;149:835-44.

27 Losse A, Henderson SE, Elliman D, Hall D, Knight E, Jongmans M. Clumsiness in children - do they grow out of Jongmans M. Clumsiness in children-do they grow out of
it? A 10-year follow-up study. Dev Med Child Neurol it? A 10-year

28 Marlow N, Roberts BL. Outcome at 8 years for children with birth weight of $1250 \mathrm{~g}$ or less. Arch Dis Child 1993; 68:286-90. 